Journal of
ISSN: 2474-7580

Case Report

Volume 10 Issue 4 - May 2018

DOI: $10.19080 /$ JOCCT.2018.10.555791

\section{Post Myocardial Infarction Ventricular Septal Defect}

\author{
Shashank Singh ${ }^{1,}$ Ashwad Afzal ${ }^{1,}$ Max Benson $^{1}$ and Iosif Gulkarov ${ }^{2,3}$ \\ ${ }^{1}$ Department of Medicine, New-York-Presbyterian Brooklyn Methodist Hospital, USA \\ ${ }^{2}$ Department of Cardiothoracic Surgery, New-York-Presbyterian Brooklyn Methodist Hospital, USA \\ ${ }^{3}$ Department of Cardiothoracic Surgery, Weill Cornell Medicine, USA
}

Submission: March 15, 2018; Published: May 14, 2018

*Corresponding author:Ashwad Afzal, MD, Department of Medicine, New-York-Presbyterian Brooklyn Methodist Hospital, $5066^{\text {th }}$ Street, Brooklyn, New York 11215, USA, Tel: (718)780-5246; Fax: (718)780-3259; Email: Ashwad.afzal@gmail.com

\begin{abstract}
ST segment elevation myocardial infarction (STEMI) is a well described medical emergency with significant strides in medical management drastically improving survival, however its complications are less frequently described. It can be a difficult task to determine the cause of an acute decompensation after successful revascularization of a STEMI. The differential includes a myriad of acute medical and surgical emergencies, including re-occlusion, stent thrombosis, and mechanical dysfunction of the free wall, septum or valves. Among these is the rare and often fatal acquired ventricular septal defect (VSD). A high index of suspicion of this complication is necessary for early recognition to improve survival. We present a case of an 83-year-old male who after 14 days of a hospital admission for STEMI with successful revascularization had an acute decompensation from hypoxemia refractory to oxygen supplementation requiring emergent intubation and hemodynamic instability requiring multiple pressor support. He was noted to have a new holosystolic murmur and a bedside transthoracic echocardiogram showed a large left-toright shunt, evident for a VSD. He underwent successful repair of the VSD and was discharged on postoperative day 42.
\end{abstract}

Keywords: Ventricular septal defect; Myocardial infarction

\section{Introduction}

An acquired Ventricular Septal Defect (VSD) is one of three major mechanical complications of an acute myocardial infarction (MI); the others being free wall rupture and papillary muscle rupture. VSD was first described in vivo in 1923 by Brunn and the first clinical criteria for its diagnosis was established in 1934 by Sager [1], however was not until 1956 that Cooley [2] reported the first case of post MI VSD repair. There is a reported incidence of acquired VSD of 1-2\% usually 3-5 days after an acute MI but it has been reported as late as 14 days post MI with a mortality rate of $\sim 60-70 \%$ [3]. The incidence of these catastrophic complications has dramatically decreased thanks to reperfusion therapy and was reported as tenfold lower in the GUSTO-1 trial [4]. We present a case of a patient with a late acquired VSD that encapsulates the clinical challenges of a prompt diagnosis and its implications on favorable outcome.

\section{Case Presentation}

An 84-year-old male with a past medical history of atrial fibrillation, presented with a 3 hour history of persistent chest tightness and shortness of breath associated with nausea. An urgent electrocardiogram (ECG) revealed ST segment elevations and q waves predominantly in leads V2-6 (Figure 1). An emergent left heart catheterization revealed a $100 \%$ occlusion of the mid left anterior descending artery (LAD), and a $60 \%$ lesion in the distal left circumflex artery (LCx). He underwent successful percutaneous coronary intervention (PCI) of LAD with a drug eluting stent; the door-to-balloon time was 55 minutes. Post PCI, he had a transthoracic echocardiogram (TTE) showing an ejection fraction (EF) of $40-45 \%$ with a kinesis of the mid-apical anterior, anteroseptal, apical septal and apical walls.

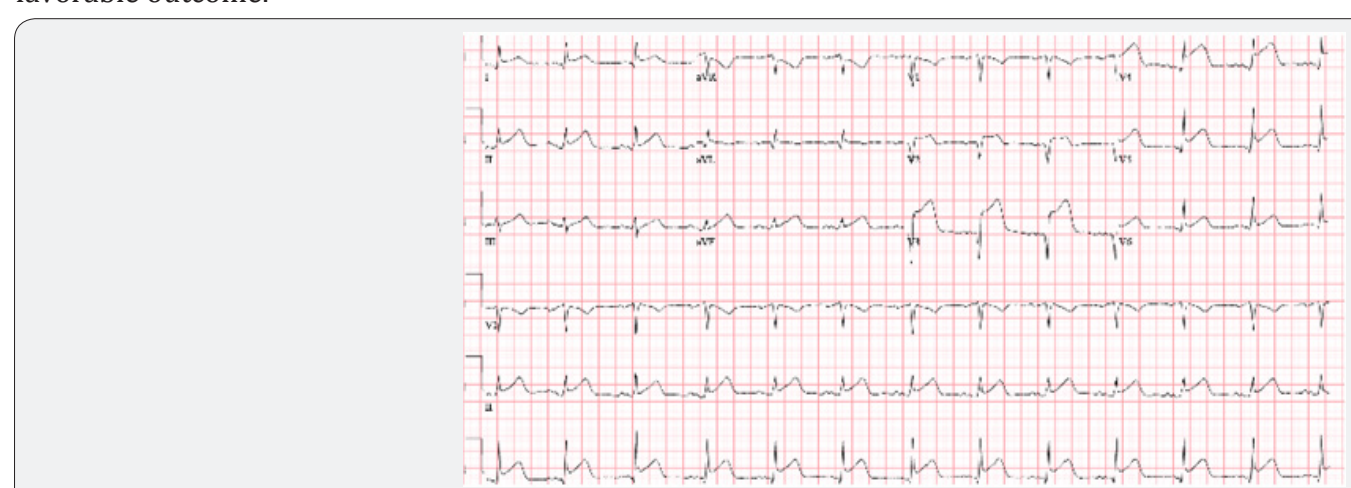

Figure 1: ST segment elevation in anterolateral leads with septal involvement (Circles). 

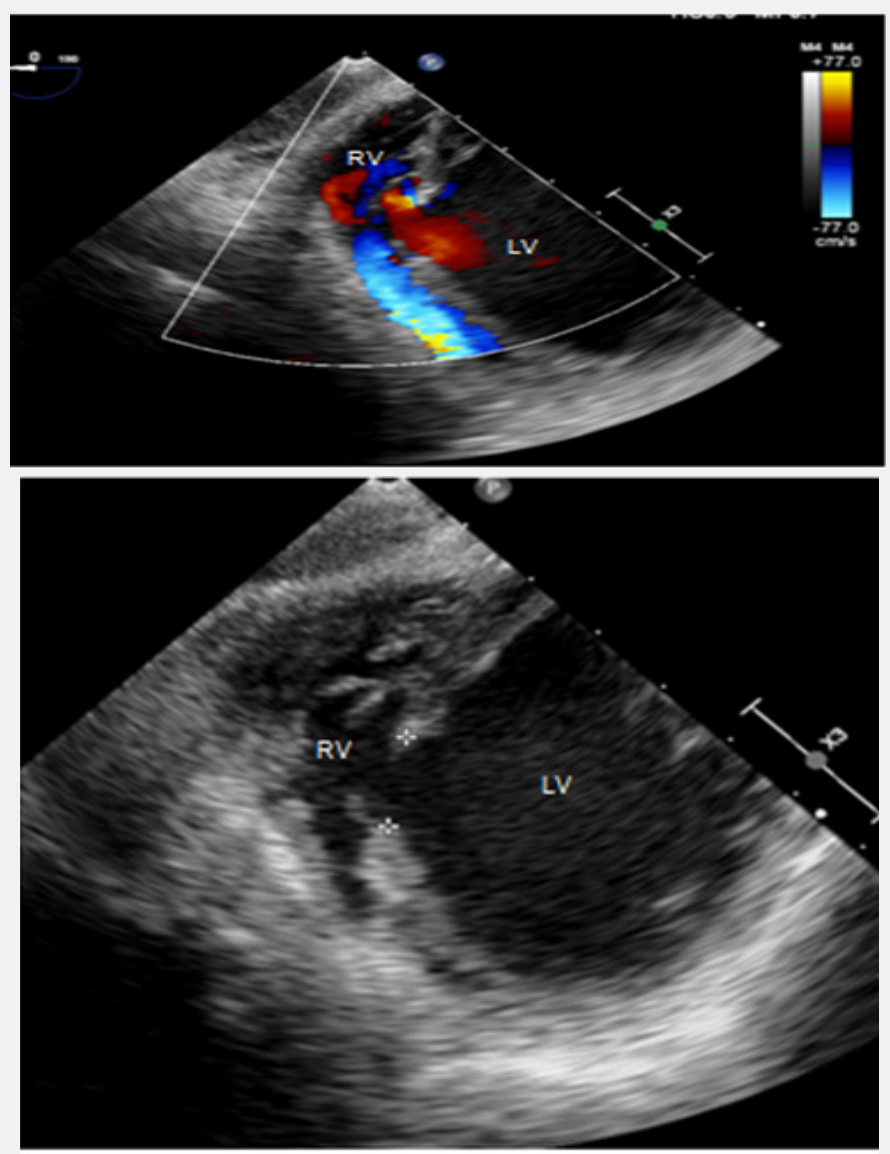

Figure 2: Trasesophageal echocardiogram short axis.

Patient was optimized medically with dual antiplatelet therapy, beta-blockers, angiotensin converting enzyme inhibitor, and statin therapy, however his initial course was complicated by acute hypoxic respiratory failure attributed to increased pulmonary congestion and aspiration pneumonia, treated with diuretic and antibiotic therapy. Concurrently, patient had developed an atrial tachycardia with persistent ST elevations that was treated with amiodarone, converting back to sinus rhythm. On day 14 of hospital course, patient acutely became short of breath, tachycardic and hypotensive resulting in hypoxemic respiratory failure with new pleural effusions. He developed hemodynamic compromise requiring pressor support and intubation with mechanical ventilation. A bedside TTE revealed a large VSD, better visualized with a transesophageal echocardiogram (TEE; Figure 2), with bilateral pleural effusion and decreased left ventricular EF of $21 \%$ for which an intra-aortic balloon pump was placed for hemodynamic support. The patient subsequently developed shock liver with coagulopathy and acute renal failure requiring continuous renal replacement therapy. Gradually, the patient's pressor requirements decreased with improvement in liver and renal function. On day 20, patient underwent a repair of a VSD without intraoperative complications. Intraoperatively, the VSD measured $3 \times 3 \mathrm{~cm}$ with relatively viable surrounding tissue. Closure of the VSD was performed with a Hemashield patch (Figure 3-6).

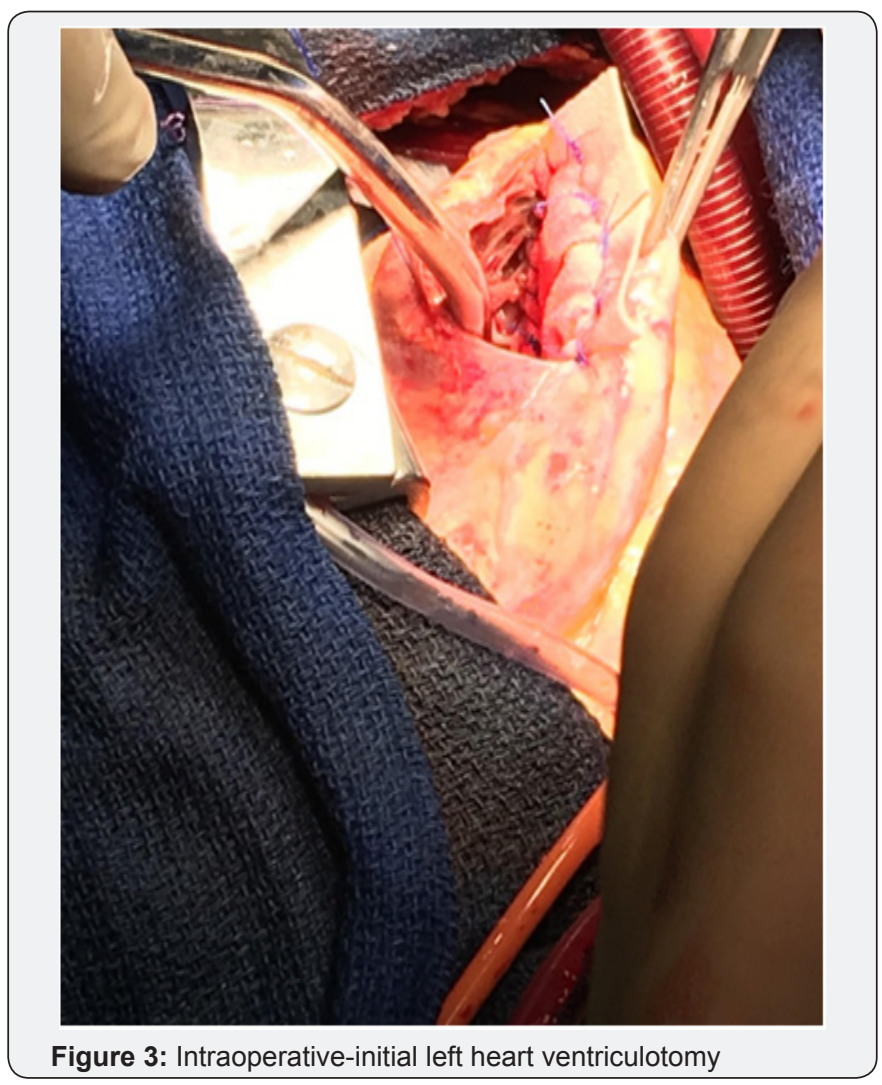




\section{Journal of Cardiology \& Cardiovascular Therapy}
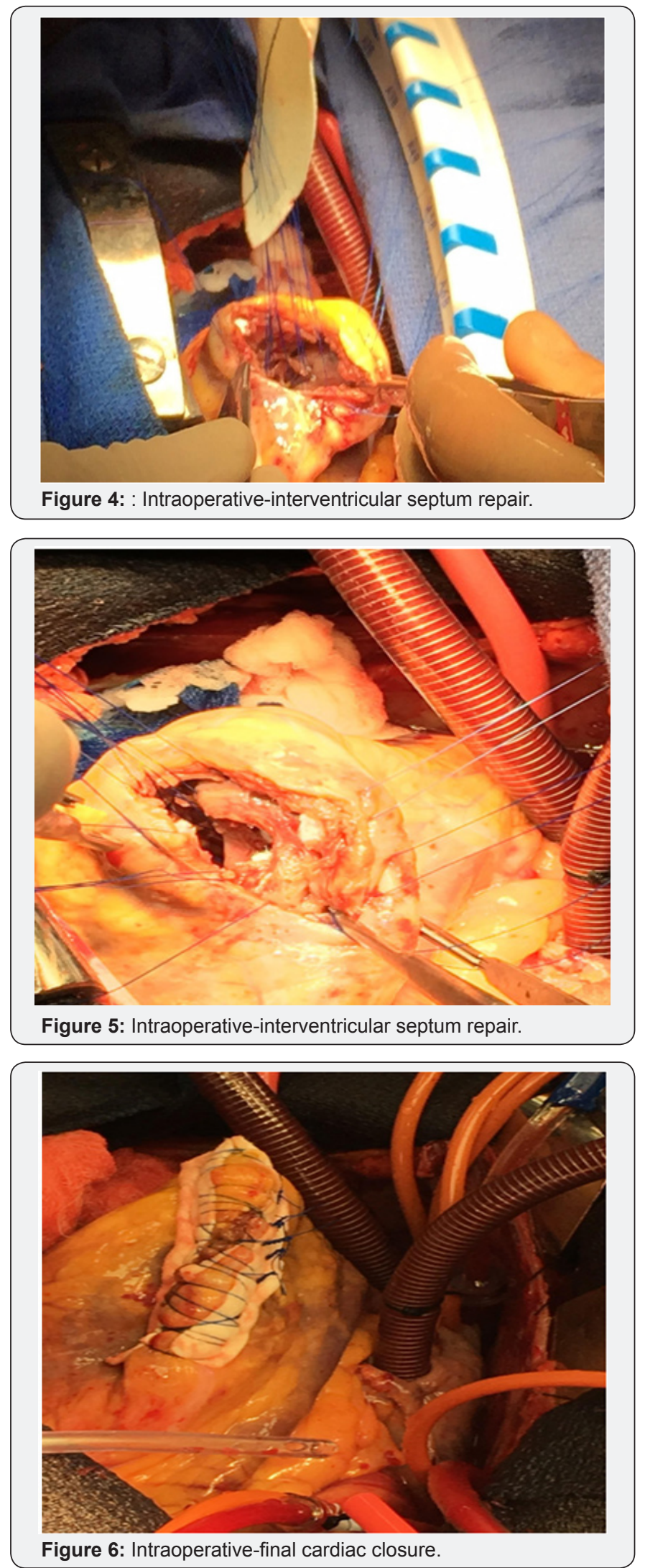

Discussion

The success of this case can be attributed to the early recognition of the VSD. Thus, recognizing the clinical presentation is paramount. We discuss the risk factors and predictors of survival, pathogenesis, clinical presentation, diagnosis and management of an acquired VSD. Risk factors for developing VSD include gender, age, current smoking history, and the affected diseased vessel [4]. Increased risk is seen in men compared to women (3:2 ratio), a mean age of 62.5 , patients with single-vessel disease (especially LAD), extensive myocardial damage, and poor septal collateral circulation [3-7]. Factors that affect mortality vary among the literature; age, gender, type of rupture, timing of surgery, pre and post-operative cardiogenic shock or renal failure have been reported to be both significant and non-significant predictors of survival [3,8-10]. Serpytis et al. [11] report that female sex, advanced age, arterial hypertension, anterior wall MI, absence of previous MI, and late arrival are all associated with a higher risk of mortality. However, multiple reports have been made that the time from symptom onset of MI to operation is the most important risk factor determining operative mortality and intra-hospital survival, reporting that early surgical intervention carries a higher mortality $[8,11,12]$.

The pathogenesis of a post MI VSD is complex. A post infarction, necrotic myocardium lacks cellular structural integrity. A rupture usually develops at the margin of the necrotic and non-necrotic myocardium; there are 2 defined types of rupture: 1) A Simple Rupture and 2) Complex Rupture [9]. On a cellular level, these ruptures are caused by local destruction secondary to infarction causing fragmentation and degeneration of myocytes further complicated by enzymatic destruction $[9,13]$. Simple rupture is located in the anterior septum and is associated with an LAD infarct: it is a direct "through-and-through" defect with a linear tract. In contrast, complex defects have dissecting tracts where the site of entry (from LV) is remote, or not in a direct, linear plane, from the site of exit (to RV) [13]. This connection between the two ventricles causes a pathologic left-to-right shunt, with the degree of shunting depending on the size of the defect. The shunt manifests as right ventricular volume overload resulting in a decreased cardiac output. In combination with an acute left-to-right shunt, often bundle branch blocks occur secondary to deterioration of the septal conduction system leading to cardiogenic shock [9].

Patients often present as a typical recovery of an uncomplicated MI, leading to sudden hemodynamic deterioration [14]. The timing of septal rupture has been documented from days to weeks, however most commonly is in the first week [12]. Often, progression of patients with an acute VSD starts with new onset, recurrent chest pain progressing to biventricular failure (predominantly right sided) and acute hypoxic respiratory failure $[9,13,14]$. A hallmark presentation for making the diagnosis for us was the patient's acute hypoxic respiratory failure refractory to oxygen supplementation, suggesting a shunt formation. These symptoms and presentation may overlap with free wall and papillary muscle rupture requiring imaging to make the definitive diagnosis $[9,14]$. Echocardiography is a fundamental imaging modality, as it is noninvasive and easily accessible, allowing for rapid diagnosis $[7,9,13,14]$. Diagnosis from echocardiogram is 
largely from saline contrast visualization and doppler imaging rather than direct visualization [7], however, the limitations of echocardiography is the underestimation of the size of the VSD [15]. Further diagnosis studies include catheterization, both of the right and left heart and cardiac magnetic resonance imaging [9].

The definitive management for an acquired VSD is surgical closure of the VSD $[9,14,15]$. There is an increased risk of mortality with a reduced rupture to surgery time secondary to the friability of the damaged tissue as mortality is the greatest immediately after rupture. Although reviews suggest that up to $25 \%$ of patients with post MI VSD with no surgical intervention died in the first 24 hours, and nearly $50 \%$ in the first week, it is common practice to make all attempts to stabilize and medically optimize patients prior to surgery [14]. Stabilization with an intraaortic balloon pump is often used to augment coronary perfusion and end-organ perfusion from improved cardiac output to delay surgical intervention $[9,13]$. The idea behind medically treating cardiogenic shock is to allow time for the necrotic myocardium to have increased scarred tissue and fibrosis for a more secured repair; acutely injured myocardium has increased friability and is less likely to be able to hold a suture $[8,9,15]$. In conclusion, post MI VSDs are catastrophic complications with a high mortality despite current advances. Although, operative management is essential, pre and post-operative clinical care are significant in increasing the survivability of the patient. In our case, the patient was 14 days post successful reperfusion therapy with a promising recovery prior to acute clinical deterioration. Even with successful operative management, the patient had significant post-operative complications, however was adequately managed with an eventual successful hospital discharge.

\section{References}

1. Sager R (1934) Coronary thrombosis: perforation of the infarcted interventricular septum. Arch Intern Med 53(1): 140-152.

2. Cooley DA, Belmonte BA, Zeis LB, Schnur S (1957) Surgical repair of ruptured interventricular septum following acute myocardial infarction. Surgery 41(6): 930-937.
3. Deja MA, Szostek J, Widenka K, Szafron B, Spyt TJ, et al. (2000) Post Infarction ventricular septal defect-can we do better. Eur J Cardiothorac Surg 18(2): 194-201.

4. Crenshaw BS, Granger CB, Birnbaum Y, Pieper KS, Morris DC, et al. (2000) Risk factors, angiographic patterns, and outcomes in patients with ventricular septal defect complicating acute myocardial infarction. GUSTO-I (Global Utilization of Streptokinase and TPA for Occluded Coronary Arteries) Trial Investigators. Circulation 101(1): 27-32.

5. Radford MJ, Johnson RA, Daggett WM, Fallon JT, Buckley MJ, et al. (1981) Ventricular septal rupture: a review of clinical and physiologic features and an analysis of survival. Circulation 64(3): 545-553.

6. Skehan JD, Carey C, Norrell MS, de Belder M, Balcon R, et al. (1989) Patterns of coronary artery disease in post-infarction ventricular septal rupture. Br Heart J 62(4): 268-272.

7. Prêtre R, Rickli H, Ye Q, Benedikt P, Turina MI (2000) Frequency of collateral blood flow in the infarct-related coronary artery in rupture of the ventricular septum after acute myocardial infarction. Am J Cardiol 85(4): 497-499.

8. Jeppsson A, Liden H, Johnsson P, Hartford M, Radegran K (2005) Surgical repair of post infarction ventricular septal defects: a national experience. Euro J Cardiothor Surg 27(2): 216-221.

9. Michael SF, Jason R (2012) Post myocardial infarction ventricular septal defect. In: Stefano N (Ed.), Front Lines of Thoracic Surgery, ISBN: 978-953-307-915-8.

10. Cummings RG, Califf R, Jones RN, Reimer KA, King YH, et al. (1989) Correlates of survival in patients with post infarction ventricular septal defect. Ann Thorac Surg 47(6): 824-830.

11. Pranas S, Karvelyte N, Serpytis R, Kalinauskas G, Rucinskas K, et al. (2015) Post-infarction ventricular septal defect: risk factors and early outcomes. Hellenic Journal of Cardiology 56(1): 66-71.

12. Akshavy M, Pooja S (2008) Post-infarction ventriculer septal defect-a case report. Kardiologia Polska 66: 5.

13. Davies, Ryan R, Michael PR, Michael AC (2014) 31: Mechanical complications of myocardial infarction. In: David Y, Luca V, Stephen Y, John RD (Eds.), Johns Hopkins Textbook of Cardiothoracic Surgery, McGraw-Hill Companies, New York, USA, 2: 439-500.

14. Reeder GS (1995) Identification and treatment of complications of myocardial infarction. Mayo Clin Proc 70(9): 880-884.

15. Drobac M, Gilbert B, Howard R, Baigrie R, Rakowski H (1983) Ventricular septal defect after myocardial infarction: diagnosis by twodimensional contrast echocardiography. Circulation 67(2): 335-341.

\begin{tabular}{l} 
Your next submission with Juniper Publishers \\
will reach you the below assets \\
- Quality Editorial service \\
- Swift Peer Review \\
- Reprints availability \\
- E-prints Service \\
- Manuscript Podcast for convenient understanding \\
- Global attainment for your research \\
- Manuscript accessibility in different formats \\
( Pdf, E-pub, Full Text, Audio) \\
- Unceasing customer service \\
Track the below URL for one-step submission \\
https://juniperpublishers.com/online-submission.php \\
\hline
\end{tabular}

